\title{
Evaluation of the Sustaining Effects of Tai Chi Qigong in the Sixth Month in Promoting Psychosocial Health in COPD Patients: A Single-Blind, Randomized Controlled Trial
}

\author{
Aileen W. K. Chan, ${ }^{1}$ Albert Lee, ${ }^{2}$ Diana T. F. Lee, ${ }^{1}$ Janet W. H. Sit, ${ }^{1}$ and S. Y. Chair ${ }^{1}$ \\ ${ }^{1}$ The Nethersole School of Nursing, The Chinese University of Hong Kong, Shatin, N.T., Hong Kong \\ ${ }^{2}$ The Jockey Club School of Public Health and Primary Care, The Chinese University of Hong Kong, Shatin, N.T., Hong Kong \\ Correspondence should be addressed to Aileen W. K. Chan; aileenchan@cuhk.edu.hk
}

Received 18 August 2013; Accepted 8 September 2013

Academic Editors: B. Balbi and O. Braendli

Copyright ( 2013 Aileen W. K. Chan et al. This is an open access article distributed under the Creative Commons Attribution License, which permits unrestricted use, distribution, and reproduction in any medium, provided the original work is properly cited.

\begin{abstract}
Objectives. To evaluate the sustaining effects of Tai Chi Qigong (TCQ) in improving the psychosocial health in chronic obstructive pulmonary disease (COPD) patients in the sixth month. Background. COPD affects both physical and emotional aspects of life. Measures to minimize patients' suffering need to be implemented. Methods. 206 COPD patients were randomly assigned into three groups: TCQ group, exercise group, and control group. The TCQ group completed a three-month TCQ program, the exercise group practiced breathing and walking exercise, and the control group received usual care. Results. Significant group-by-time interactions in quality of life (QOL) using St. George's respiratory questionnaire $(P=0.002)$ and the perceived social support from friends using multidimensional scale of perceived social support $(P=0.04)$ were noted. Improvements were observed in the TCQ group only. Conclusions. TCQ has sustaining effects in improving psychosocial health; it is also a useful and appropriate exercise for COPD patients.
\end{abstract}

\section{Introduction}

Chronic obstructive pulmonary disease (COPD) ranks as the fourth leading cause of death worldwide [1]. In terms of morbidity, COPD ranks 13th. The World Health Organization estimates that the disease will become the third global killer by 2030. COPD is a progressive disease, and the lung functions of COPD patients may continue to deteriorate [2]. Manifestations of COPD include fatigue, weakness, activity intolerance, and dyspnoea. As the disease worsens, its signs and symptoms become more obvious, and the patient's ability to perform daily activities is affected [3]. Patients may become increasingly dependent on others, may stop participating in activities, and finally may isolate themselves [4]. The effect of the disease on both physical and emotional aspects of life may lead to disability and an impaired emotional state [5], which would in turn influence the quality of life. If COPD patients are better supported and cared for, these negative psychosocial consequences may be prevented or mitigated
[6]. Therefore, measures to minimize patients' suffering need to be implemented [7]. With existing evidence supporting the benefits of exercise in COPD patients [8], Tai Chi Qigong may be an alternative exercise for this group of people. Tai Chi Qigong is a form of gentle exercise suitable for older adults and relatively frail people because it can be mastered without much exertion $[9,10]$. These known characteristics of Tai Chi Qigong match with the background of COPD patients who may not have good physical statuses.

Qigong is an ancient Chinese system of gentle self-healing exercises that are designed to cultivate functional integrity and enhance the life vital energy called Qi. Tai chi is a martial art that can be viewed as a therapeutic exercise. Tai chi practice involves the recognition, development, and use of $Q i$. This vital energy flows in the body along channels called meridians and collaterals, which connect all the organ systems and tissues. When $Q i$ is abundant, flowing freely, and in balance, a person usually enjoys good health and longevity. However, when $Q i$ becomes deficient, excessive, 
stagnant, or blocked, diseases will occur. Tai chi and Qigong can be combined to promote good circulation of $Q i$ in the body. These techniques can be learned and practiced by people with various problems to maintain general health and wellness. The health benefits of Tai Chi Qigong, particularly in COPD patients, have been rarely studied in healthcare research, so a randomized controlled trial was conducted to address this knowledge gap and to investigate the shortterm therapeutic effect of Tai Chi Qigong in COPD patients [11]. After the three-month intervention period, the effect of practicing Tai Chi Qigong on health-related quality of life (HRQL) was observed in symptom and activity domains using the St George's respiratory questionnaire (SGRQ). Given that Tai Chi Qigong is a complex exercise routine that requires considerable practice to attain proficiency, whether its effects are sustained over a longer time frame must be investigated. Therefore, this study explored the sustaining effects of Tai Chi Qigong on HRQL and its longer-term effects on perceived social support in the sixth month from baseline with continuing regular self-practice of Tai Chi Qigong.

\section{Methods}

2.1. Study Design and Methods. This study used a singleblind, randomized controlled trial with repeated measures. Research assistants for data collection were blind to the study to minimize researcher bias.

2.2. Subjects and Study Setting. The subjects were recruited from five general outpatient clinics; informed consent was obtained prior to the study. Ethical approval and permissions for conducting the study in the selected general outpatient clinics were also obtained. Inclusion criteria for subject recruitment were the following: clinically diagnosed with COPD, as defined by the American Thoracic Society [12], and able to walk independently. Subjects were excluded if they had suffered from severe sensory or cognitive impairment, symptomatic ischemic heart disease, or had practiced Tai Chi Qigong within a year prior to the commencement of the study.

2.3. Sample Size and Randomization. The sample size was based on previous findings on the medium effect of Tai Chi Qigong exercises on HRQL in COPD patients [13]. With a power of 0.80 , at a $5 \%$ significant level of repeated measure ANOVA, 52 subjects per group were required [14]. To cover for the potential attrition rate of $25 \%$ [15], a total of 206 subjects were recruited and randomly assigned to one of the three groups, namely, Tai Chi Qigong (TCQ) group $(n=70)$, exercise group $(n=69)$, and control group $(n=67)$. Random allocation was done by a computer-generated randomizer [16].

2.4. Intervention. Subjects in the TCQ group completed a Tai Chi Qigong program consisting of two 60-minute sessions each week for three months. They were advised to continue daily self-practice of Tai Chi Qigong upon completion of the instructor-led program. Subjects in the exercise group were taught to practice breathing exercise combined with walking as an exercise. They were also advised to self-practice the breathing and walking exercises daily. A diary was given to the subjects in both the TCQ and exercise groups to record the frequency of their self-practice.

Subjects in the control group were instructed to maintain their usual daily activities. No extra exercise was recommended. To enhance the internal validity of the study findings, participants in the exercise and control groups were designated to join nonexercise community activities in the three-month Tai Chi Qigong training period. The purpose of this arrangement was to maintain regular gatherings for all participants to balance the emotional effect of the extra weekly gatherings of the TCQ group during the process of Tai Chi Qigong training.

During the study period, all subjects continued their prescribed medical treatments. Data collections were performed at baseline (T1), sixth week (T2), third month (T3), and sixth month (T4).

2.5. Outcome Measures. The outcome measures were HRQL using SGRQ, clinical significance of SGRQ using minimum clinically important difference (MCID), and self-perceived social support using multidimensional scale of social support (MSPSS).

SGRQ is a disease-specific measure of HRQL in COPD patients. Score ranges from 0 to 100 , where 0 indicates "best health" and 100 indicates "worst health" [17]. SGRQ has been tested to be a valid, sensitive, and reliable instrument that can be used to assess HRQL in western and Chinese people with COPD $[18,19]$. Cronbach's $\alpha$ ranges from 0.74 to 0.95 . Testretest reliability shows intraclass correlation coefficients of all the dimensions exceeding $0.70(P<0.001)$.

MCID is defined as the smallest difference in the client perceived as beneficial or important $[20,21]$. It is used to evaluate the clinical significance of the effects of SGRQ perceived by patients. The threshold for each of the SGRQ domains is 4 units [22].

MSPSS is a 12-item questionnaire that examines the selfperceived social support from social relationships, including family, friends and significant others [23]. It uses a sevenpoint Likert scale set from 1 (strongly disagree) to 7 (strongly agree). The total score ranges from 12 to 84, with higher scores indicating higher levels of perceived support. The psychometric properties of the Chinese version demonstrate high internal consistency, with a Cronbach's $\alpha$ equal to 0.89 ; its validity and reliability have been confirmed [24].

2.6. Statistical Analysis. Data analyses were conducted using SPSS version 18.0. Descriptive statistics were used to describe the demographic characteristics of the sample. Repeated measure analysis of covariance (ANCOVA) was used to examine the outcome measures. A $P$ value of 0.05 was used as the level of statistical significance. An intention-to-treat analysis was applied in calculating the missing values. In case of withdrawals, the data of the last observation were carried forward [25]. 


\section{Results}

A total of 206 subjects participated in this study, among which 158 completed the study program at the third month. The attrition rate was $23.8 \%$. A total of 128 subjects (TCQ group $=50$, exercise group $=46$, and control group $=32$ ) received follow-up assessment in the sixth month (Figure 1). No statistically significant differences were observed in the demographic data among the three study groups, except for gender (Table 1). This finding was ascribed to the lesser number of females $(9.2 \%)$ who participated in this study. The obvious difference in the number of male and female participants may be because of the fact that COPD is more common in men [26]. Therefore, the confounding effect of gender was controlled as a covariate in the data analyses.

Table 2 presents the descriptive statistics and the results of repeated measures ANCOVA of SGRQ. Improvements were shown in all domains of the SGRQ in the TCQ group, whereas deteriorations were noted both in the exercise group and in the control group. Significant group-by-time interaction effects revealed group differences across time, with the TCQ group having statistical improvement in symptom domain $(F$ $(6,606)=3.959, P<0.001)$, activity domain $(F(6,606)$ $=2.418, P=0.026)$, impact domain $(F(6,606)=2.344$, $P=0.030)$, and total SGRQ score $(F(6,606)=3.510, P=$ 0.002 ) across the six-month study period compared with the exercise and control groups (Figure 2).

Improvements in self-perceived symptom score by 4.6 units, activity score by 2.5 units, impact score by 1.6 units, and total score by 2.4 units were observed in the TCQ group over the six-month study period. Deteriorations were noted in the exercise group in the symptom score by 2.3 units, activity score by 6.0 units, impact score by 4.6 units, and total score by 4.6 units from baseline to the sixth month. Worsening health status was found in all aspects in the control group. The declines were indicated by the increase of symptom score by 5.2 units, activity score by 4.5 units, impact score by 4.7 units, and total score by 4.7 units.

For SGRQ, a decrease of more than 4 units in the score is indicative of clinical significance with positive functional change [27]. The current study reported a statistically significant improvement in HRQL in the TCQ group. However, apart from the symptom domain, the statistically significant results were not clinically significant. By contrast, the exercise group demonstrated clinically significant deterioration in all findings, except in the symptom domain. Worsening health status was found in all aspects of the SGRQ, which was clinically significant in the control group (Figure 3).

Regarding the multidimensional scale of perceived social support, significant time-by-group interaction effect was noted in the perceived social support from friends $(F(4.68$, $472.47)=2.338, P=0.044)$, with improvement $(+16.6 \%)$ found in the TCQ group (Figure 4$)$. No differences were found in the perceived social support from family $(P=0.602)$ and significant others $(P=0.101)$ and in the total score $(P=0.056)$. Furthermore, no significant changes were found in perceived social support both in the exercise and control groups (Table 3, Figure 4).

\section{Discussion}

Psychological well-being is an important factor in rehabilitation for chronic illnesses. The effect of COPD on HRQL has been extensively explored in the United States and in Europe ( $n=3265$ ), with $61 \%$ of COPD patients stating that their health is fair to very poor [28]. This study adopted SGRQ to measure the HRQL of COPD patients. SGRQ is one of the most widely used disease-specific health status measures for COPD. It has been tested in a group of healthy subjects ( $n=74)$, and the mean scores for the symptom, activity, impact, and total scores are 12, 9, 2, and 6, respectively [19]. In this study, the COPD participants reported a low level of HRQL at baseline using SGRQ, and the mean scores for the four captioned domains were 41,52, 33, and 40, respectively, indicating that their HRQL was affected by the disease. These findings concur with the existing evidence that COPD affects HRQL [29].

Previous studies have shown that the beneficial effects on HRQL are gained during inpatient pulmonary rehabilitation; however, the effects decrease and cannot be sustained after discharge $[29,30]$. The findings may be ascribed to the fact that patients revert to their prerehabilitation sedentary lifestyles after being discharged from hospitals. The other reason may be the severely impaired health status in COPD patients, which impedes their ability to achieve a higher response to rehabilitation programs. Patients with moderate to severe COPD are often unable to sustain high-intensity exercise. Therefore, the low-intensity Tai Chi Qigong exercise with 3.1 MET [31] was adopted as intervention for the COPD patients in this study. This intensity of Tai Chi Qigong exercise was well tolerated and enjoyed by the participants. The perceived positive effects elicited demands from the COPD patients to continue the Tai Chi Qigong exercise upon completion of the three-month training program. Majority of the participants (93\%) continued practicing Tai Chi Qigong after they learned the skills. The positive effects were reflected on their adherence to regular Tai Chi Qigong practice and the significant improvements in their HRQL within three months on a low-intensity Tai Chi Qigong program conducted twice a week. The results were substantial after another three months of self-practice, suggesting that additional health gains could be derived from a longer period of practice. By contrast, subjects in the other two groups perceived a continued deteriorating trend in HRQL from baseline to the sixth month, which matched with the literature stating that COPD patients exhibit progressive decline in physiological and psychosocial functions [2, 32]. Tai Chi Qigong appeared to be more beneficial than the popular breathing and walking exercises often used as pulmonary rehabilitation intervention in COPD patients.

4.1. Social Support. Subjective perceived social support is important in improving health management and in adhering to the demanding treatment regimen of COPD patients [7, 33]. Thus, interventions should include efforts to strengthen social networks. No prior study has examined the effect of Tai Chi Qigong on social support among COPD patients. In 


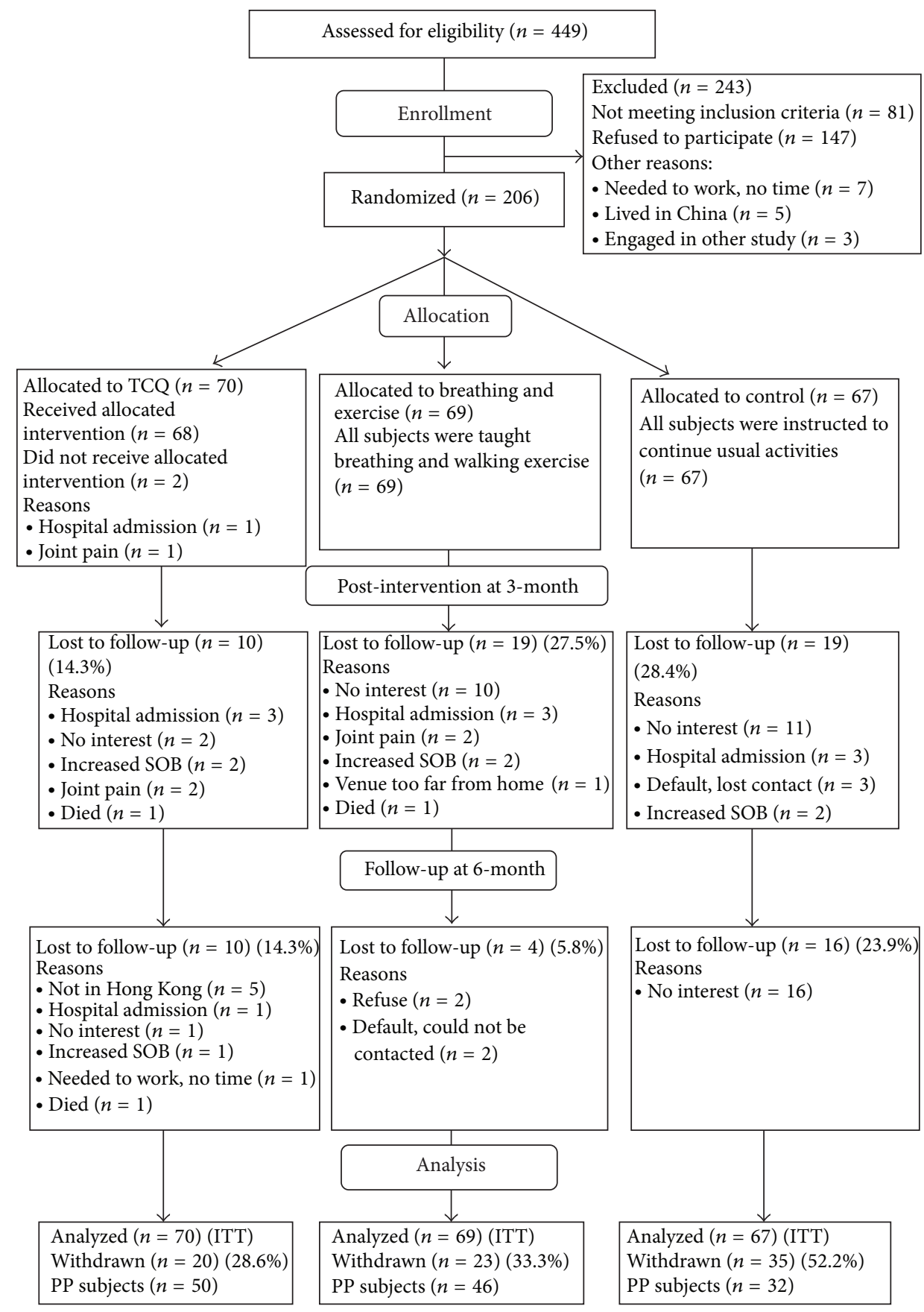

FIGURE 1: CONSORT (2005) flowchart to track participants through randomized controlled trail. ITT: intention to-treat; PP: per protocol [39].

the current study, the effectiveness of Tai Chi Qigong in promoting perceived social support in patients was investigated. MSPSS was adopted for the measurement of social support. Baseline findings showed that the participants perceived best social support from family members with the mean item score of 5.45, which fell well above the midpoint of 3.5. The mean item score of perceived social support from significant others was 3.74, which fell around the midpoint of 3.5, indicating that the participants perceived themselves to be fairly supported by their significant others. The perceived social support from friends was the lowest among the three categories, with the mean item score of 3.21, which fell below the midpoint of 3.5 , suggesting that the participants perceived themselves having a limited social support network from friends. This finding concurred with previous local studies in the Chinese elderly, which reported that the social support for Chinese older adults mainly came from family members $[34,35]$. The high average mean for family support in the current study is also congruent with other local studies by Jiang et al. [36] in Chinese COPD patients. This observation 
TABLE 1: Demographic and baseline data of subjects by group allocation [11]*

\begin{tabular}{|c|c|c|c|c|}
\hline & $\operatorname{TCQ}(n=70)$ & Exercise $(n=69)$ & Control $(n=67)$ & $P$ value \\
\hline Age (Year), mean (SD) & $71.7(8.2)$ & $73.6(7.5)$ & $73.6(7.4)$ & 0.24 \\
\hline Gender & & & & $0.02^{*}$ \\
\hline Male (\%) & $69(99)$ & $61(88)$ & $58(87)$ & \\
\hline Female (\%) & $1(1)$ & $8(12)$ & $9(13)$ & \\
\hline Years of COPD, mean (SD) & $10.3(9.3)$ & $10.6(8.8)$ & $12.4(10.6)$ & 0.32 \\
\hline Marital status & & & & 0.51 \\
\hline Married (\%) & $64(91.4)$ & $60(87.0)$ & $54(80.6)$ & \\
\hline Single $(\%)$ & $1(1.4)$ & $0(0.0)$ & $2(3.0)$ & \\
\hline Separated (\%) & $1(1.4)$ & $1(1.4)$ & $2(3.0)$ & \\
\hline Widowed (\%) & $4(5.7)$ & $8(11.6)$ & $9(13.4)$ & \\
\hline Live with & & & & 0.30 \\
\hline Alone (\%) & $4(5.7)$ & $4(5.8)$ & $8(11.9)$ & \\
\hline Family (\%) & $66(94.3)$ & $65(94.2)$ & $59(88.1)$ & \\
\hline Education level & & & & 0.38 \\
\hline Illiteracy (\%) & $9(12.9)$ & $10(14.5)$ & $14(20.9)$ & \\
\hline Primary (\%) & $41(58.6)$ & $47(68.1)$ & $37(55.2)$ & \\
\hline Secondary (\%) & $18(25.7)$ & $9(13.0)$ & $15(22.4)$ & \\
\hline Tertiary or above $(\%)$ & $2(2.9)$ & $3(4.3)$ & $1(1.5)$ & \\
\hline Religious beliefs & & & & 0.33 \\
\hline Yes $(\%)$ & $28(40.0)$ & $30(43.5)$ & $26(38.8)$ & \\
\hline No $(\%)$ & $42(60.0)$ & $39(56.5)$ & $41(61.2)$ & \\
\hline Smoking status & & & & 0.81 \\
\hline Second hand smoker (\%) & $1(1.4)$ & $2(2.9)$ & $3(4.5)$ & \\
\hline Never smoke (\%) & $2(2.9)$ & $4(5.8)$ & $3(4.5)$ & \\
\hline Ex-smoker (\%) & $55(78.6)$ & $47(68.1)$ & $46(68.7)$ & \\
\hline Current smoker (\%) & $12(17.1)$ & $16(23.2)$ & $15(22.4)$ & \\
\hline Stage of COPD & & & & 0.50 \\
\hline Mild (\%) & $7(10)$ & $13(19)$ & $12(18)$ & \\
\hline Moderate (\%) & $31(44)$ & $26(38)$ & $29(43)$ & \\
\hline Severe $(\%)$ & $32(46)$ & $30(43)$ & $26(39)$ & \\
\hline \multicolumn{5}{|l|}{ Coexisting diseases } \\
\hline Heart disease (\%) & $9(13)$ & $10(15)$ & $6(9)$ & 0.58 \\
\hline $\mathrm{HT} \mathrm{( \% )}$ & $28(40)$ & $36(52)$ & $28(42)$ & 0.21 \\
\hline $\mathrm{DM}(\%)$ & $7(10)$ & $6(9)$ & $7(10)$ & 0.95 \\
\hline No co-existing disease (\%) & $16(23)$ & $16(23)$ & $20(30)$ & 0.13 \\
\hline SGRQ-HKC, mean (SD) & $42.7(15.1)$ & $37.0(16.6)$ & $39.4(16.2)$ & 0.11 \\
\hline Total MSPSS-C, mean (SD) & $50.3(18.1)$ & $50.2(17.1)$ & $46.6(16.4)$ & 0.38 \\
\hline
\end{tabular}

could be explained in the Chinese tradition that people tend to maintain strong and cohesive bond between family members, indicating they have a limited social network size.

Social support is a high-level functioning factor for improving psychosocial health. Previous studies have reported positive effects of group exercise on psychological health for clients with similar diseases [37]. Group intervention provides a psychological and socialization context for support, and this intervention matches with the TCQ group intervention in this study. Although individual exercise can result in psychological enhancement, group dynamics further improve such opportunities. Tai Chi Qigong would help subjects improve their concept of self, which would increase their intention to adopt a particular course of health- or illness-related action [38]. 
TABLE 2: Comparison of SGRQ at baseline, 6th week, 3rd month, and 6th month.

\begin{tabular}{|c|c|c|c|c|c|c|c|c|}
\hline & TCQ & $(n=70)$ & Exerci & se $(n=69)$ & Contr & $\mathrm{col}(n=67)$ & & \\
\hline & Mean (SD) & $\begin{array}{c}\text { Change from last } \\
\text { measurement } \\
M(\%)\end{array}$ & Mean (SD) & $\begin{array}{c}\text { Change from last } \\
\text { measurement } \\
\mathrm{M}(\%)\end{array}$ & Mean (SD) & $\begin{array}{c}\text { Change from last } \\
\text { measurement } \\
\mathrm{M}(\%)\end{array}$ & $\begin{array}{c}\text { Time }{ }^{*} \text { group } \\
P \text { value }\end{array}$ & $\begin{array}{c}\text { Partial eta } \\
\text { squared }\end{array}$ \\
\hline Symptoms & & & & & & & $<0.001^{*}$ & 0.038 \\
\hline Baseline (T1) & $45.75(18.54)$ & & $38.64(19.44)$ & & 37.89 (19.39) & & & \\
\hline 6 th week (T2) & $45.50(17.85)$ & $-0.25(-0.55)$ & $36.38(20.24)$ & $-2.26(-5.85)$ & $42.86(18.96)$ & $4.97(13.12)$ & & \\
\hline $\begin{array}{l}\text { 3rd month } \\
\text { (T3) }\end{array}$ & $42.18(19.03)$ & $-3.32(-7.30)$ & 37.44 (18.17) & $1.06(2.91)$ & $42.37(20.07)$ & $-0.49(-1.14)$ & & \\
\hline $\begin{array}{l}\text { 6th month } \\
\text { (T4) }\end{array}$ & 41.11 (21.09) & $-1.07(-2.54)$ & 40.90 (19.79) & $3.46(9.24)$ & 43.13 (19.72) & $0.76(1.79)$ & & \\
\hline Activity & & & & & & & $0.026^{*}$ & 0.023 \\
\hline Baseline (T1) & $56.05(19.82)$ & & $47.03(21.65)$ & & $51.69(21.24)$ & & & \\
\hline 6 th week (T2) & $52.43(20.63)$ & $-3.62(-6.46)$ & $52.43(20.32)$ & $5.40(11.48)$ & $53.42(20.10)$ & $1.73(3.35)$ & & \\
\hline $\begin{array}{l}\text { 3rd month } \\
\text { (T3) }\end{array}$ & $54.43(19.50)$ & $2.00(3.81)$ & $53.51(22.11)$ & $1.08(2.06)$ & $54.10(18.22)$ & $0.68(1.27)$ & & \\
\hline $\begin{array}{l}\text { 6th month } \\
\text { (T4) }\end{array}$ & $53.52(22.27)$ & $-0.91(-1.67)$ & $53.05(20.45)$ & $-0.46(-0.86)$ & $56.17(18.56)$ & $2.07(3.83)$ & & \\
\hline Impact & & & & & & & $0.030^{*}$ & 0.023 \\
\hline Baseline (T1) & 34.11 (16.72) & & 30.67 (18.79) & & $32.77(18.53)$ & & & \\
\hline 6th week (T2) & $33.46(17.10)$ & $-0.65(-1.91)$ & $32.70(18.56)$ & $2.03(6.62)$ & 34.20 (16.59) & $1.43(4.36)$ & & \\
\hline $\begin{array}{l}\text { 3rd month } \\
\text { (T3) }\end{array}$ & $34.41(17.34)$ & $0.95(2.84)$ & 33.79 (17.85) & 1.09 (3.33) & $37.63(16.72)$ & $3.43(10.03)$ & & \\
\hline $\begin{array}{l}\text { 6th month } \\
\text { (T4) }\end{array}$ & $32.49(18.29)$ & $-1.92(-5.58)$ & $35.27(18.67)$ & $1.48(4.38)$ & 37.48 (16.81) & $-0.15(-0.40)$ & & \\
\hline Total SGRQ & & & & & & & $0.002^{*}$ & 0.034 \\
\hline Baseline (T1) & $42.69(15.13)$ & & $36.97(16.56)$ & & 39.37 (16.18) & & & \\
\hline 6th week (T2) & $41.22(15.78)$ & $-1.47(-3.44)$ & $39.31(15.66)$ & $2.34(6.33)$ & 41.48 (15.39) & $2.11(5.36)$ & & \\
\hline $\begin{array}{l}\text { 3rd month } \\
\text { (T3) }\end{array}$ & 41.77 (15.18) & $0.55(1.33)$ & $40.39(16.10)$ & $1.08(2.75)$ & $43.41(14.77)$ & $1.93(4.64)$ & & \\
\hline $\begin{array}{l}\text { 6th month } \\
\text { (T4) }\end{array}$ & $40.29(16.94)$ & $-1.48(-3.54)$ & 41.60 (15.74) & $1.21(3.00)$ & 44.09 (15.01) & $0.68(1.57)$ & & \\
\hline
\end{tabular}

SGRQ: St George's respiratory questionnaire.

Score ranges from 0 to 100 , where " 0 " indicates the best health and " 100 " indicates the worst health.

${ }^{*} P<0.05$ for test of repeated measures ANCOVA.

During the first three months of the Tai Chi Qigong training period, arrangements were made for all subjects in the current study to attend regular weekly gatherings. Although the outcome of perceived social support was insignificant during the first three months, it became substantial on the sixth month follow-up assessment. This finding may be due to the majority (93\%) of the participants in this group who continued their daily Tai Chi Qigong practice in groups informally after the completion of the threemonth Tai Chi Qigong program. Some of the participants in this group eventually became friends. Notably, some participants came to the research center together during the six-month follow-up assessment, proving that their social network had been broadened after participating in the Tai Chi Qigong program and explaining why they experienced an improved level of satisfaction in perceived social support from friends at the study endpoint. Thus, social support needs time to build rapport and solid relationships among the participants. Moreover, social support may have influenced the participants' motivation to continue the Tai Chi Qigong exercise. Encouragement from their social support may have influenced the positive clinical and statistical significance for the TCQ group. The Tai Chi Qigong program is believed to create a supportive atmosphere for sharing interests and beliefs, which can then foster social support among the participants. 


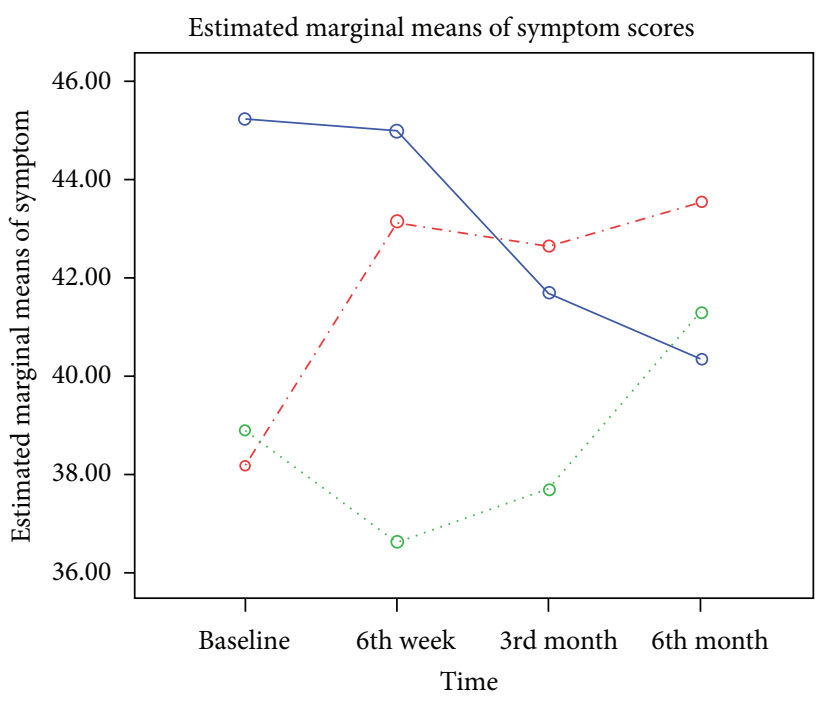

(a)

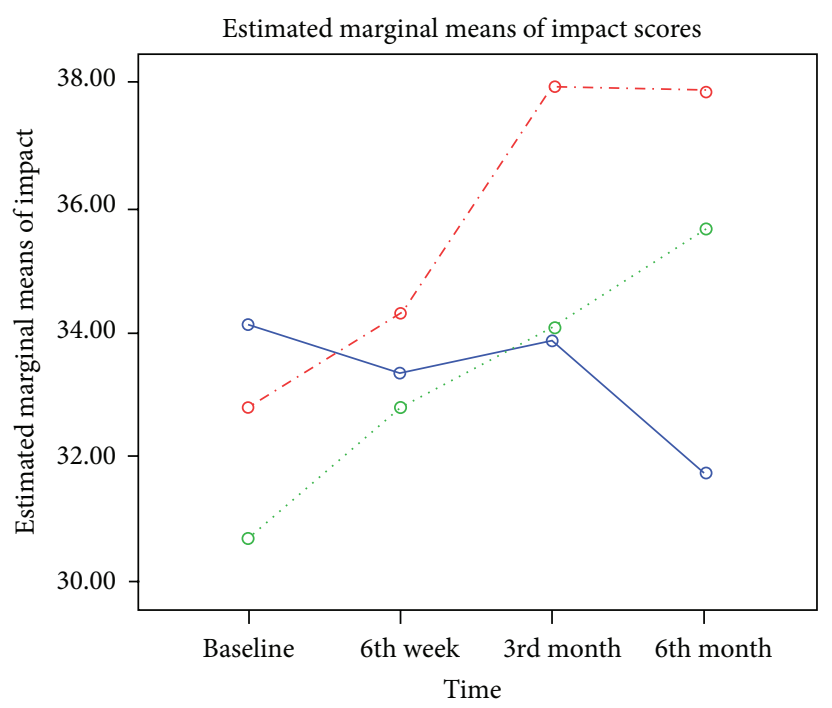

Group

— Tai chi

..... Exercise

-.. Control

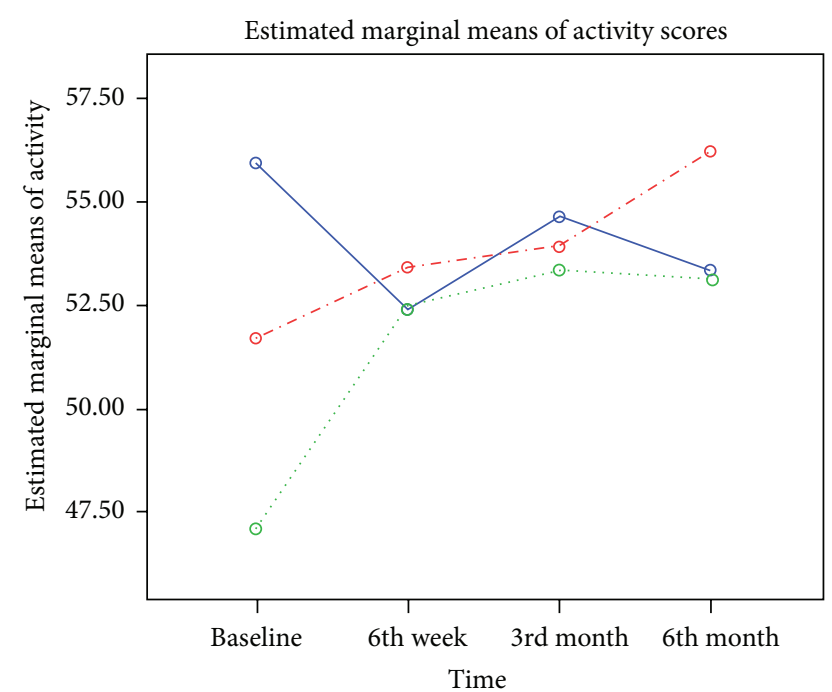

(b)

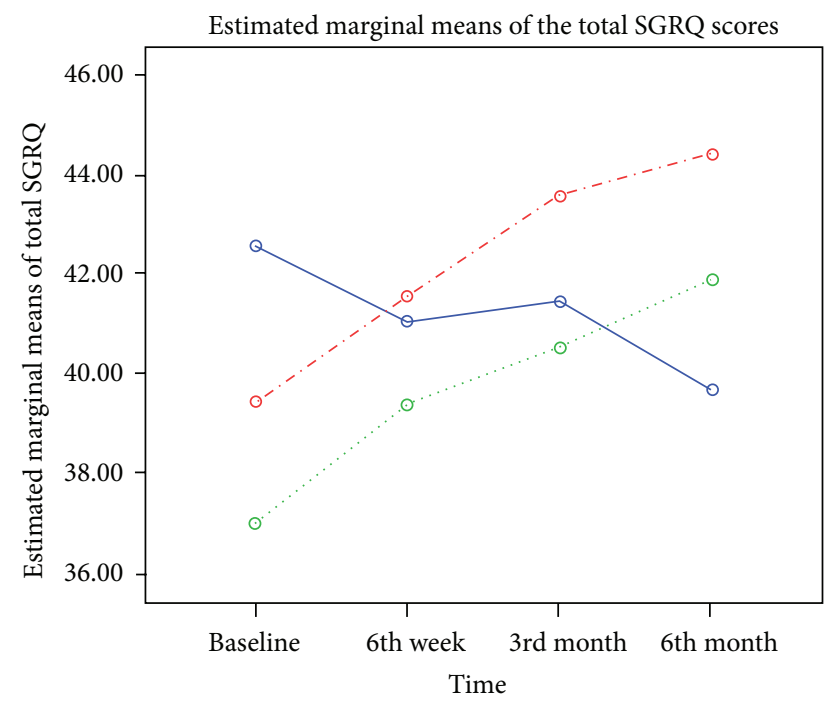

Group

— Tai chi

Exercise

-.- Control

(c)

(d)

FIGURE 2: Mean scores of the four domains of St George's respiratory questionnaire (SGRQ) among the three study groups from baseline to 6th month.

The exercise group and the control group did not show any significant changes in the perceived social support throughout the six-month study period. From the informal observation during the community activity classes, the participants did interact with one another; however, the interaction was limited to casual and superficial conversations. Expression in whatever form showing support and caring was rarely noticed. After the three-month class was completed, the participants did not have any continued interactions. Thus, although the community activities had created an environment for sharing of interest, such sharing was superficial, and the strength was not sufficient to facilitate the development of social support among the participants.

4.2. Limitations. First, the excessive attrition rate recorded in the control group could contribute to limitation, to a certain degree, in maintaining sample representativeness. The high attrition may have affected the validity of study results. Future studies should plan attractive placebo activities and arrange a Tai Chi Qigong wait-list plan in the control 


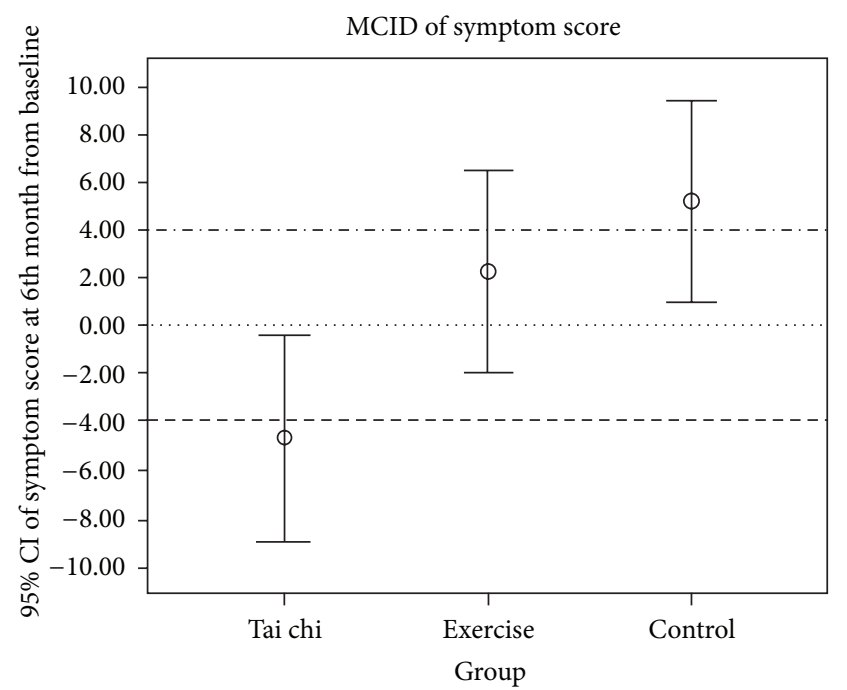

(a)

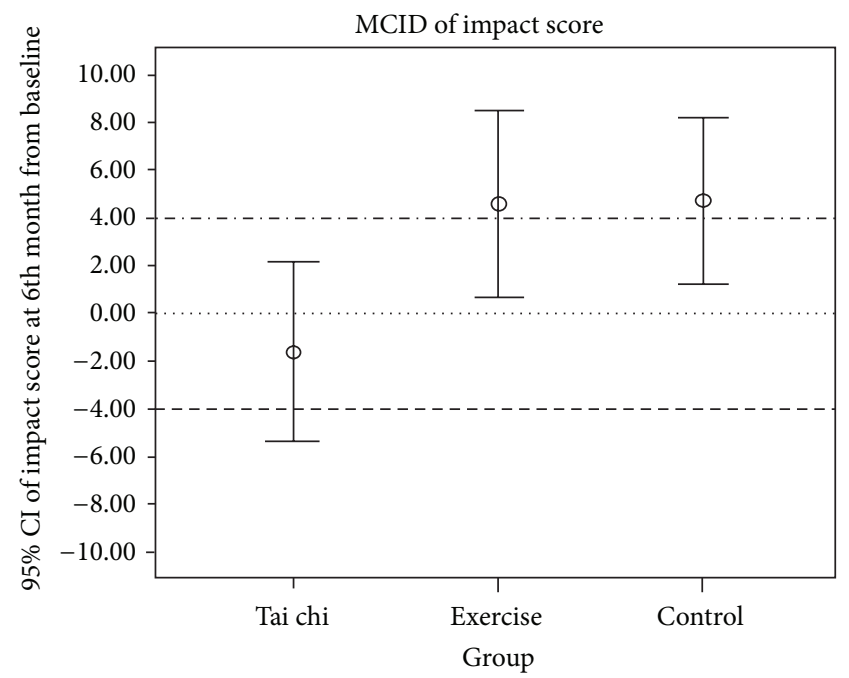

(c)

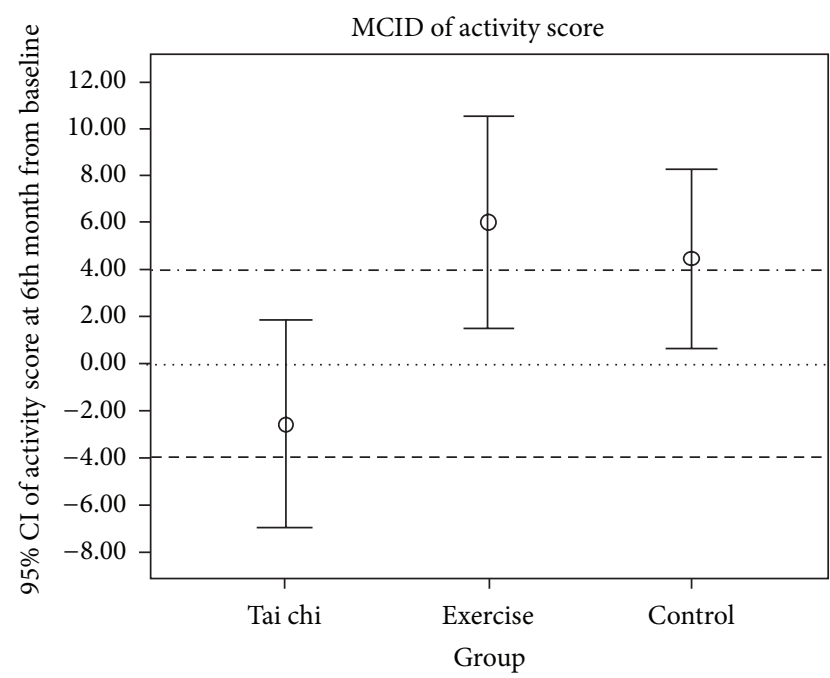

(b)

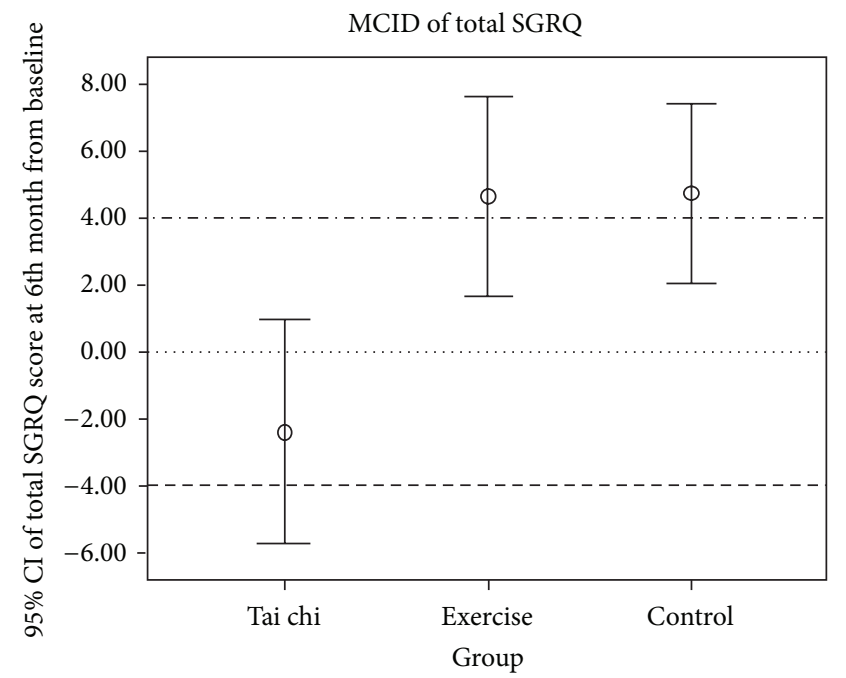

(d)

FIGURE 3: Minimum clinically important difference (MCID): changes in the St. George's respiratory questionnaire (SGRQ) scores at 6th month from baseline. $\circ$ Circles represent the mean; whiskers represent 95\% confidence intervals; (dotted line) no change from baseline; (dashed line) $(-4)$ threshold for positive clinical significance; (double-dotted line) $(+4)$ threshold for negative clinical significance.

groups to retain participants and minimize attrition. Second, owing to the small number of female participants enrolled in this study, gender differences on the Tai Chi Qigong effects could not be examined. Future studies should recruit more female subjects, if available, so that gender differences on the therapeutic effects of Tai Chi Qigong can be evaluated.

4.3. Implications for Clinical Practice. The study provided new evidence that Tai Chi Qigong could be beneficial for long-term health promotion in COPD patients. In addition, Tai Chi Qigong is a safe and feasible intervention that causes no harm to the patients. Integrating Tai Chi Qigong into patients' daily activities provides a good opportunity for them to actively and independently participate in activities. Given that Tai Chi Qigong is a low-technology and gentle exercise, it is particularly appropriate and favorable for people with COPD as they are usually diagnosed at their later years of life and their physical functions have deteriorated because of normal aging process and disease progression. Tai Chi Qigong can work in conjunction with therapeutic treatment regimens and act as an alternative choice of exercise for health promotion and health maintenance in COPD patients.

\section{Conclusions}

The HRQL of individuals with COPD is affected by deteriorated physical functions, and their need for social support is increased. The three-month Tai Chi Qigong program indicates that Tai Chi Qigong is effective in psychosocial improvement among COPD patients. Continued self-practicing Tai 
TABLE 3: Comparison of MSPSS at baseline, 6th week, 3rd month, and 6th month.

\begin{tabular}{|c|c|c|c|c|c|c|c|c|}
\hline & TCQ & $(n=70)$ & Exerci & $\operatorname{se}(n=69)$ & Contr & ol $(n=67)$ & & \\
\hline & Mean (SD) & $\begin{array}{c}\text { Change from last } \\
\text { measurement } \\
\mathrm{M}(\%)\end{array}$ & Mean (SD) & $\begin{array}{c}\text { Change from last } \\
\text { measurement } \\
\mathrm{M}(\%)\end{array}$ & Mean (SD) & $\begin{array}{c}\text { Change from last } \\
\text { measurement } \\
\text { M (\%) }\end{array}$ & $\begin{array}{c}\text { Time }{ }^{*} \text { group } \\
P \text { value }\end{array}$ & $\begin{array}{c}\text { Partial eta } \\
\text { squared }\end{array}$ \\
\hline Family & & & & & & & 0.602 & \\
\hline Baseline (T1) & $21.50(6.24)$ & & 22.55 (5.77) & & $21.39(6.86)$ & & & \\
\hline 6th week (T2) & $22.07(6.48)$ & $0.57(2.65)$ & $23.58(5.42)$ & $1.03(4.57)$ & $22.30(5.23)$ & $0.91(4.25)$ & & \\
\hline $\begin{array}{l}\text { 3rd month } \\
\text { (T3) }\end{array}$ & $23.11(5.98)$ & $1.04(4.71)$ & $23.45(5.02)$ & $-0.13(-0.55)$ & $23.00(5.41)$ & $0.70(3.14)$ & & \\
\hline $\begin{array}{l}\text { 6th month } \\
\text { (T4) }\end{array}$ & $23.39(5.50)$ & $0.28(1.21)$ & $23.19(5.41)$ & $-0.26(-1.11)$ & $22.57(5.76)$ & $-0.43(-1.87)$ & & \\
\hline Friend & & & & & & & $0.044^{*}$ & 0.023 \\
\hline Baseline (T1) & $13.93(7.87)$ & & $13.01(7.51)$ & & $11.54(7.72)$ & & & \\
\hline 6th week (T2) & $13.31(7.39)$ & $-0.62(-4.45)$ & $13.28(6.77)$ & $0.27(2.08)$ & $13.85(7.52)$ & $2.31(20.02)$ & & \\
\hline $\begin{array}{l}\text { 3rd month } \\
\text { (T3) }\end{array}$ & $14.63(7.74)$ & $1.32(9.92)$ & 12.87 (6.59) & $-0.41(-3.09)$ & $13.70(7.98)$ & $-0.15(-1.08)$ & & \\
\hline $\begin{array}{l}\text { 6th month } \\
\text { (T4) }\end{array}$ & $16.41(7.70)$ & 1.78 (12.17) & $13.25(6.93)$ & $0.38(2.95)$ & $13.40(7.37)$ & $-0.03(-2.19)$ & & \\
\hline $\begin{array}{l}\text { Significant } \\
\text { other }\end{array}$ & & & & & & & 0.101 & \\
\hline Baseline (T1) & $15.66(7.96)$ & & $14.97(7.68)$ & & $14.22(7.84)$ & & & \\
\hline 6th week (T2) & $14.87(7.88)$ & $-0.79(-5.04)$ & $15.99(7.60)$ & $1.02(6.81)$ & $15.22(7.61)$ & $1.00(7.03)$ & & \\
\hline $\begin{array}{l}\text { 3rd month } \\
\text { (T3) }\end{array}$ & $16.20(7.88)$ & $1.33(8.94)$ & $15.19(7.16)$ & $-0.08(-5.00)$ & $15.60(7.93)$ & $0.38(2.50)$ & & \\
\hline $\begin{array}{l}\text { 6th month } \\
\text { (T4) }\end{array}$ & $18.26(6.84)$ & $2.06(12.72)$ & $15.67(7.53)$ & $0.48(3.16)$ & $15.40(7.31)$ & $-0.02(-1.28)$ & & \\
\hline Total MSPSS & & & & & & & 0.056 & \\
\hline Baseline (T1) & $51.09(18.75)$ & & $50.54(16.71)$ & & 47.18 (17.16) & & & \\
\hline 6th week (T2) & $50.33(18.12)$ & $-0.76(1.49)$ & $52.84(16.21)$ & $2.30(4.55)$ & $51.37(17.14)$ & $4.19(8.88)$ & & \\
\hline $\begin{array}{l}\text { 3rd month } \\
\text { (T3) }\end{array}$ & $53.94(18.54)$ & $3.61(7.17)$ & $51.51(15.02)$ & $-1.33(-2.52)$ & $52.30(17.68)$ & $0.93(1.81)$ & & \\
\hline $\begin{array}{l}\text { 6th month } \\
\text { (T4) }\end{array}$ & $58.06(17.04)$ & $4.12(7.64)$ & $52.09(16.63)$ & & $51.37(16.73)$ & $-0.93(-1.78)$ & & \\
\hline
\end{tabular}

MSPSS: multidimensional scale of perceived social support.

The total score ranges from 12 to 84 , with higher scores indicating higher levels of perceived support.

${ }^{*} P<0.05$ for test of repeated measures ANCOVA.

Chi Qigong exercise sustains the beneficial effects for a longer period, significantly enhances HRQL, and increases self-perceived social support from friends. Its effectiveness, appropriateness, and feasibility for COPD patients make it a promising exercise option for this particular population.

\section{Abbreviation List}

ANCOVA: Analysis of covariance

ANOVA: Analysis of variance

COPD: Chronic obstructive pulmonary disease

HQOL: Health related quality of life

MCID: Minimum clinically important difference

MSPSS: Multidimensional scale of perceived social support
SGRQ: St George's respiratory questionnaire

TCQ: Tai chi Qigong.

\section{Ethical Approval}

Ethical approval was obtained from Joint the Chinese University of Hong Kong-New Territories East Cluster Clinical Research Ethics Committee.

\section{Conflict of Interests}

The authors declare that there is no conflict of interests regarding the publication of this paper. 


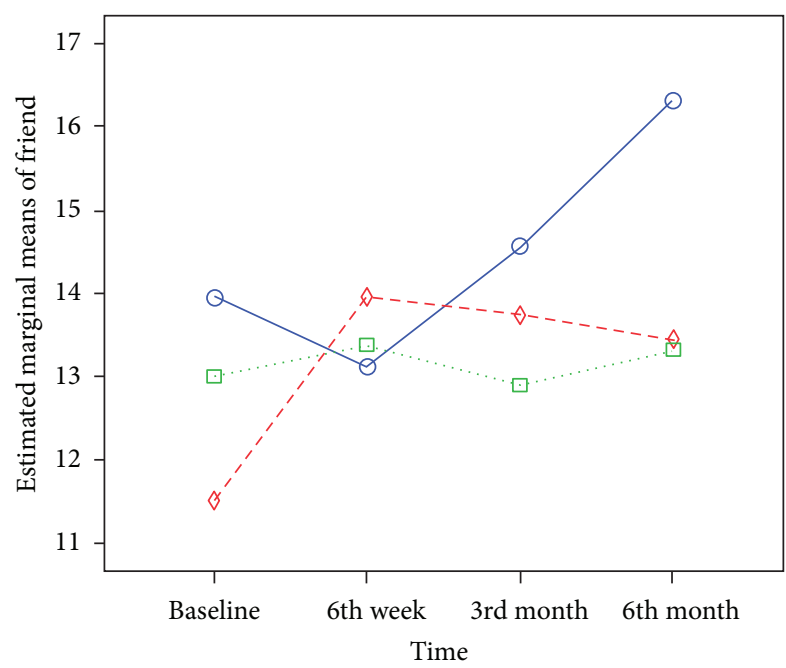

Group

- Tai chi

Exercise

- - Control

FIGURE 4: Mean scores of perceived social support from friends from baseline to 6th month.

\section{Acknowledgments}

This study was funded by: Health and Health Services Research Fund (HHSRF: 06070201), Research Office, Food and Health Bureau, 18/F, Murray Building, Garden Road, Central; Hong Kong SAR Government is acknowledged as the funding source of this study.

\section{References}

[1] World Health Organization, "Chronic obstructive pulmonary disease (COPD)," August 2013, http://www.who.int/mediacentre/factsheets/fs315/en/index.html.

[2] M. Decramer, R. Gosselink, M. Rutten-Van Mölken et al., "Assessment of progression of COPD: report of a workshop held in Leuven, 11-12 March 2004," Thorax, vol. 60, no. 4, pp. 335-342, 2005.

[3] V. M. Pinto-Plata, C. Cote, H. Cabral, J. Taylor, and B. R. Celli, "The 6-min walk distance: change over time and value as a predictor of survival in severe COPD," European Respiratory Journal, vol. 23, no. 1, pp. 28-33, 2004.

[4] S. C. C. Chan, "Chronic obstructive pulmonary disease and engagement in occupation," American Journal of Occupational Therapy, vol. 58, no. 4, pp. 408-415, 2004.

[5] R. A. Pauwels, A. S. Buist, P. M. A. Calverley, C. R. Jenkins, and S. S. Hurd, "Global strategy for the diagnosis, management, and prevention of chronic obstructive pulmonary disease," American Journal of Respiratory and Critical Care Medicine, vol. 163, no. 5, pp. 1256-1276, 2001.

[6] M. Kara and A. Mirici, "Loneliness, depression, and social support of Turkish patients with chronic obstructive pulmonary disease and their spouses," Journal of Nursing Scholarship, vol. 36, no. 4, pp. 331-336, 2004.
[7] T. T. Hansel and P. J. Barnes, An Atlas of Chronic Obstructive Pulmonary Disease: COPD, Parthenon, London, UK, 2004.

[8] World Health Organization, "WHO strategy for prevention and control of chronic respiratory diseases," August 2013, http://www.who.int/respiratory/publications/WHO_MNC_CRA_ 02.1.pdf.

[9] B. Gallagher, “Tai Chi Chuan and Qigong: physical and mental practice for functional mobility," Topics in Geriatric Rehabilitation, vol. 19, no. 3, pp. 172-182, 2003.

[10] C. Lan, S.-W. Chou, S.-Y. Chen, J.-S. Lai, and M.-K. Wong, "The aerobic capacity and ventilatory efficiency during exercise in Qigong and Tai Chi Chuan practitioners," American Journal of Chinese Medicine, vol. 32, no. 1, pp. 141-150, 2004.

[11] A. W. K. Chan, A. Lee, L. K. P. Suen, and W. W. S. Tam, "Effectiveness of a Tai chi Qigong program in promoting healthrelated quality of life and perceived social support in chronic obstructive pulmonary disease clients," Quality of Life Research, vol. 19, pp. 653-664, 2010.

[12] American Thoracic Society, "Standards for the diagnosis and management of patients with COPD," http://www.thoracic.org/statements/resources/respiratory-disease-adults/copdexecsum.pdf.

[13] S. Kiatboonsri, N. Amornputtisathaporn, S. Siriket, V. Boonsarngsuk, and C. Kiatboonsri, "Tai chi qigong exercise training in COPD," Chest, vol. 132, p. 535S, 2007.

[14] J. Cohen, “A power primer," Psychological Bulletin, vol. 112, no. 1, pp. 155-159, 1992.

[15] A. P. Verhagen, M. Immink, A. van der Meulen, and S. M. A. Bierma-Zeinstra, "The efficacy of Tai Chi Chuan in older adults: a systematic review," Family Practice, vol. 21, no. 1, pp. 107-113, 2004.

[16] Social Psychology Network, "Research randomizer," http:// www.randomizer.org/.

[17] P. W. Jones, St. George's Respiratory Questionnaire, Respiratory Medicine, St. George University of London, Hong Kong, 2003.

[18] S. Spencer, P. M. A. Calverley, P. S. Burge, and P. W. Jones, "Health status deterioration in patients with chronic obstructive pulmonary disease," American Journal of Respiratory and Critical Care Medicine, vol. 163, no. 1, pp. 122-128, 2001.

[19] D. T. W. Yu, R. J. Scudds, and R. A. Scudds, "Reliability and validity of a Hong Kong Chinese version of the St George's Respiratory Questionnaire in patients with COPD," Hong Kong Physiotherapy Journal, vol. 22, pp. 33-39, 2004.

[20] R. Jaeschke, J. Singer, and G. H. Guyatt, "Measurement of health status. Ascertaining the minimal clinically important difference," Controlled Clinical Trials, vol. 10, no. 4, pp. 407-415, 1989.

[21] Y. Lacasse, E. Wong, G. H. Guyatt, D. King, D. J. Cook, and R. S. Goldstein, "Meta-analysis of respiratory rehabilitation in chronic obstructive pulmonary disease," The Lancet, vol. 348, no. 9035, pp. 1115-1119, 1996.

[22] P. W. Jones, "Interpreting thresholds for a clinically significant change in health status in asthma and COPD," European Respiratory Journal, vol. 19, no. 3, pp. 398-404, 2002.

[23] G. D. Zimet, N. W. Dahlem, S. G. Zimet, and G. K. Farley, "The multidimensional scale of perceived social support," Journal of Personality Assessment, vol. 52, pp. 30-41, 1988.

[24] K.-L. Chou, "Assessing Chinese adolescents' social support: the multidimensional scale of perceived social support," Personality and Individual Differences, vol. 28, no. 2, pp. 299-307, 2000. 
[25] J. M. Lachin, "Statistical considerations in the intent-to-treat principle," Controlled Clinical Trials, vol. 21, no. 3, pp. 167-189, 2000.

[26] World Health Organization, "World Health Statistics 2006," http://www.who.int/whosis/whostat2006.pdf.

[27] P. W. Jones, "St. George's respiratory questionnaire: MCID," Journal of Chronic Obstructive Pulmonary Disease, vol. 2, no. 1, pp. 75-79, 2005.

[28] S. Rennard, M. Decramer, P. M. A. Calverley et al., "Impact of COPD in North America and Europe in 2000: subjects' perspective of Confronting COPD International Survey," European Respiratory Journal, vol. 20, no. 4, pp. 799-805, 2002.

[29] R. H. Green, S. J. Singh, J. Williams, and M. D. L. Morgan, "A randomised controlled trial of four weeks versus seven weeks of pulmonary rehabilitation in chronic obstructive pulmonary disease," Thorax, vol. 56, no. 2, pp. 143-145, 2001.

[30] C. A. J. Ketelaars, H. H. Abu-Saad, M. A. G. Schlösser, R. Mostert, and E. F. M. Wouters, "Long-term outcome of pulmonary rehabilitation in patients with COPD," Chest, vol. 112, no. 2, pp. 363-369, 1997.

[31] Y.-F. C. Chao, S.-Y. Chen, C. Lan, and J.-S. Lai, “The cardiorespiratory response and energy expenditure of Tai-Chi-Qui-Gong," American Journal of Chinese Medicine, vol. 30, no. 4, pp. 451461, 2002.

[32] P.-O. Bridevaux, M. W. Gerbase, N. M. Probst-Hensch, C. Schindler, J.-M. Gaspoz, and T. Rochat, "Long-term decline in lung function, utilisation of care and quality of life in modified GOLD stage 1 COPD," Thorax, vol. 63, no. 9, pp. 768-774, 2008.

[33] P. Marino, J. A. Sirey, P. J. Raue, and G. S. Alexopoulos, "Impact of social support and self-efficacy on functioning in depressed older adults with chronic obstructive pulmonary disease," International Journal of Chronic Obstructive Pulmonary Disease, vol. 3, no. 4, pp. 713-718, 2008.

[34] S. T. Cheng, C. K. L. Lee, A. C. M. Chan, E. M. F. Leung, and J. J. Lee, "Social network types and subjective well-being in Chinese older adults," The Journals of Gerontology. Series B, vol. 64, no. 6, pp. 713-722, 2009.

[35] I. Chi and K.-L. Chou, "Social support and depression among elderly Chinese people in Hong Kong," International Journal of Aging and Human Development, vol. 52, no. 3, pp. 231-252, 2001.

[36] S. Jiang, S. Chaiwan, S. Panuthai, C. Yijuan, Y. Lei, and L. Jiping, "Family support and self-care behavior of Chinese chronic obstructive pulmonary disease patients," Nursing and Health Sciences, vol. 4, no. 1-2, pp. 41-49, 2002.

[37] M. L. Galantino, K. Shepard, L. Krafft et al., "The effect of group aerobic exercise and T'ai Chi on functional outcomes and quality of life for persons living with acquired immunodeficiency syndrome," Journal of Alternative and Complementary Medicine, vol. 11, no. 6, pp. 1085-1092, 2005.

[38] K. Tones and J. Green, Health Promotion: Planning and Strategies, SAGE, London, UK, 2004.

[39] A. W. K. Chan, A. Lee, D. T. F. Lee, L. K. P. Suen, W. W. S. Tam, and P. Griffiths, "The sustaining effects of tai chi qigong on physiological health for COPD patients: a randomized controlled trial," Complementary Therapies in Medicine. In press. 


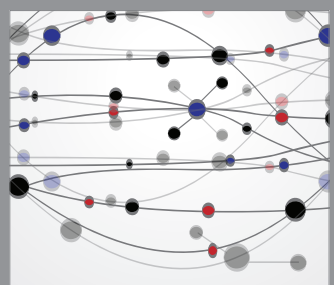

The Scientific World Journal
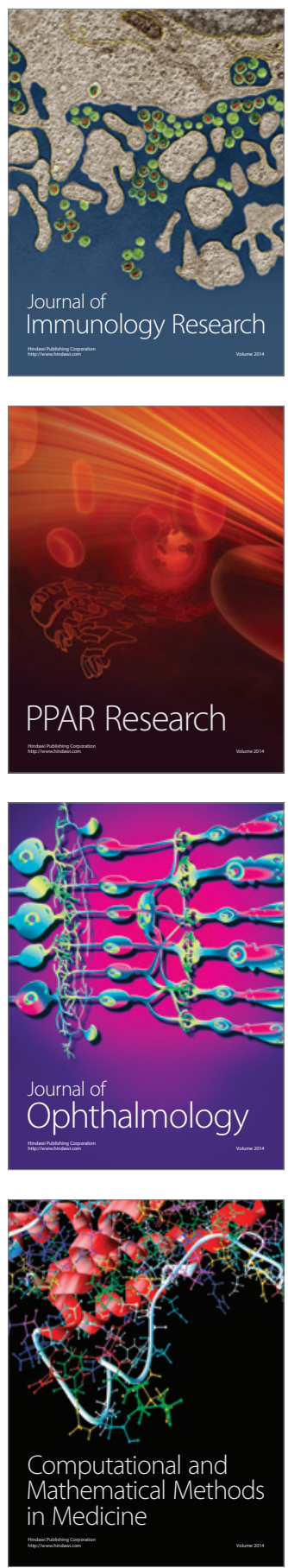

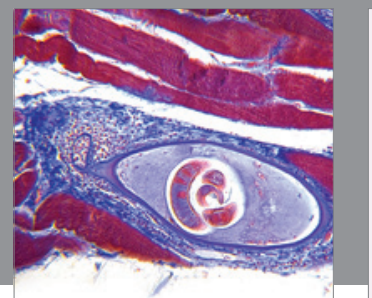

Gastroenterology

Research and Practice
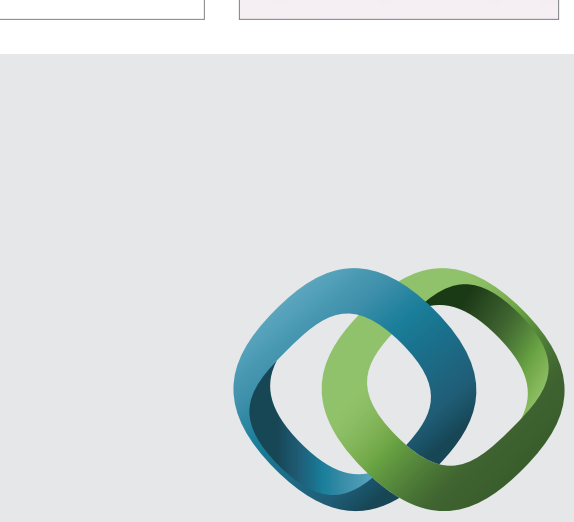

\section{Hindawi}

Submit your manuscripts at

http://www.hindawi.com
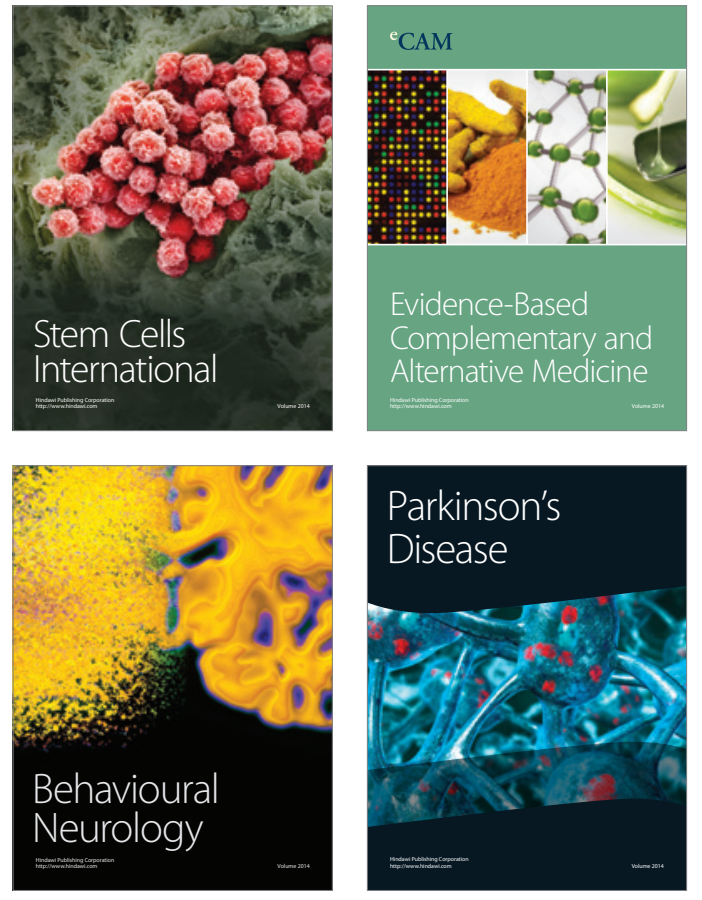
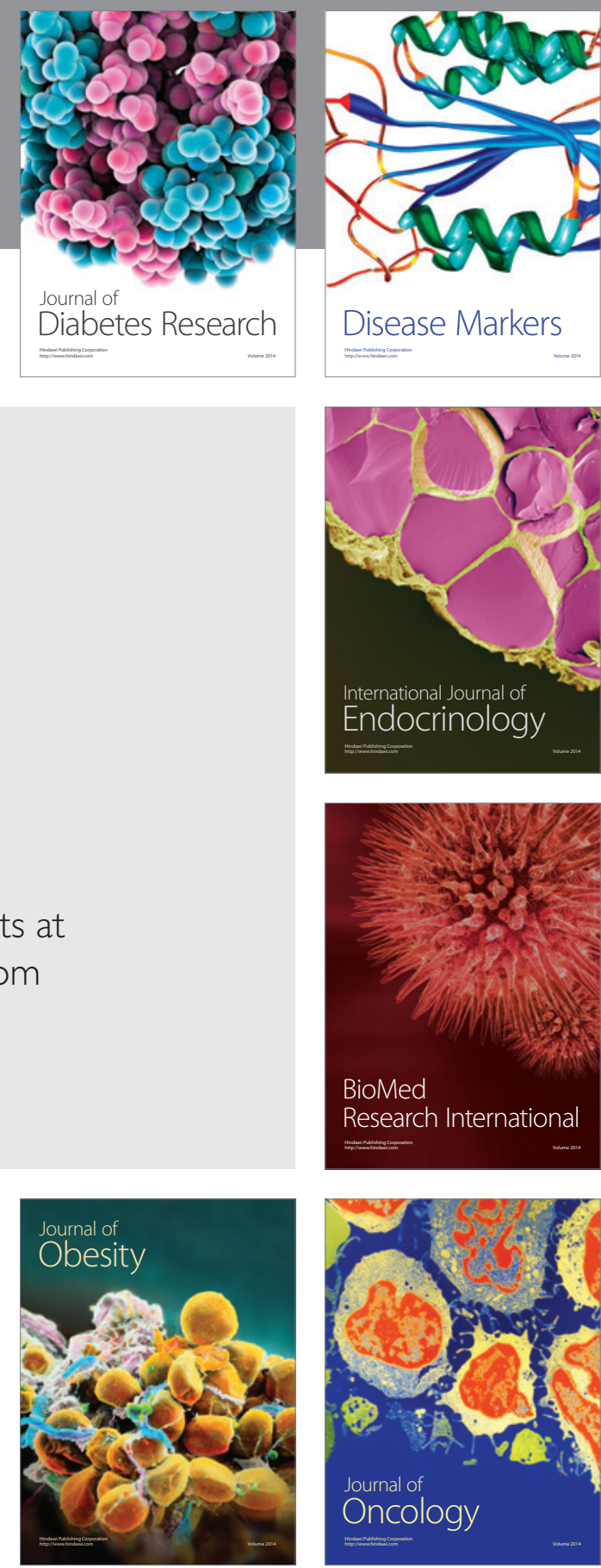

Disease Markers
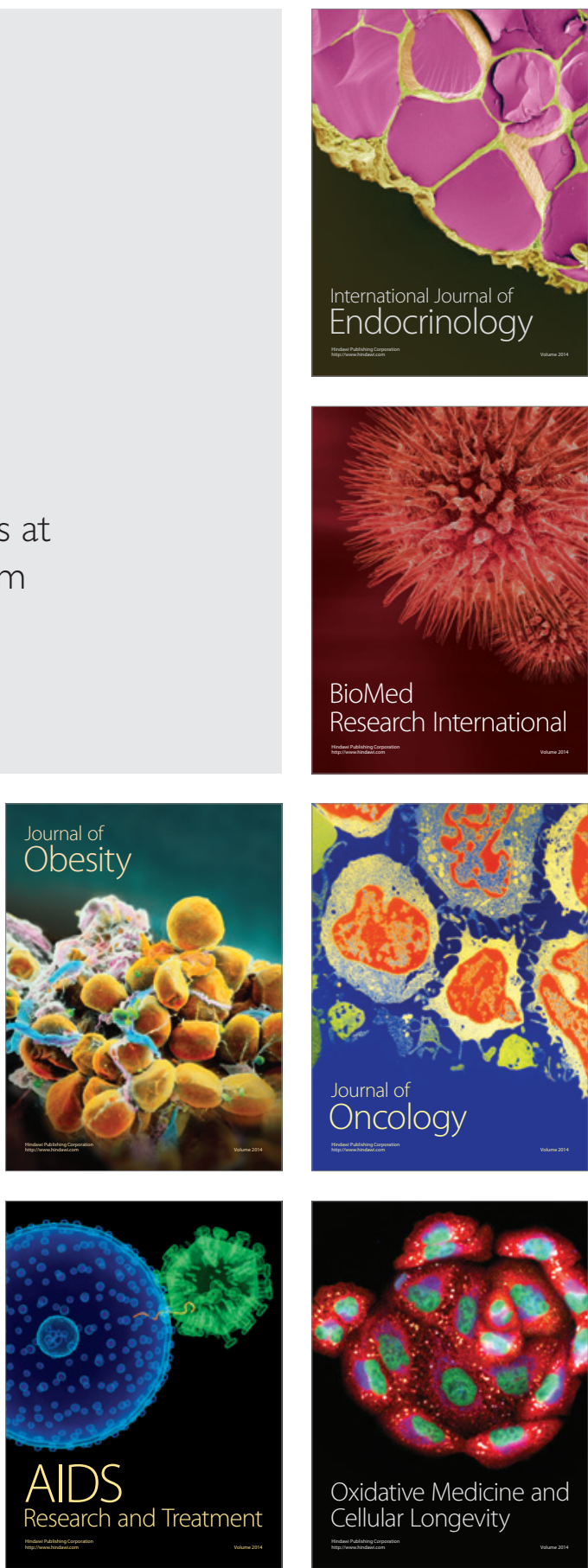